\title{
A novel pre-processing inspection methodology to enhance productivity in automotive product remanufacture: an industry-based research of 2196 engines
}

Sara J. Ridley and WL ljomah*

* Correspondence:

W.I.ijomah@strath.ac.uk

Design, Manufacture and Engineering Management, University of Strathclyde, Glasgow, UK

\begin{abstract}
Remanufacture, a process of returning used products to "as-new" condition with matching guarantee, is commercially viable where the remaining value in the used product and the final selling price are much higher than the cost of the products' rebuilding. Guide identified that remanufacturers perceive the scarcity of effective remanufacturing tools and techniques as a key threat to the industry whilst ljomah assessed the key remanufacturing issues on a five-point scale ranging from "Not Significant through to "Critical". Component inspection was the only issue rated as "critical" by all remanufacturers. Extensive work within the industry plus the detailed analysis and observation of the remanufacturing process during this research has shown that component inspection has significant bearing on overall productivity. However, the activity is undertaken in a hap-hazard manner based almost purely on experience and guesswork and lacks proper methodologies and tools. This paper presents the results of quantitative research, conducted in a Caterpillar UK Remanufacturing facility, to establish the relationship between pre-processing inspection and the subsequent remanufacturing process time for returned cores (used products).

Keywords: Remanufacturing; Pre-processing; Inspection methodology
\end{abstract}

\section{Theoretical background and industrial setting of the research}

Industry recognisable as remanufacturing has been in evidence since early in the $20^{\text {th }}$ century. It expanded during and after the Second World War largely fuelled by the need to reuse military vehicles and machinery. OEMs (Original Equipment Manufacturer) and/or their agents and dealers remanufactured their own products generally on a fairly small scale. Typical parts that were remanufactured include compressors and gearboxes. Lund [16] defined three basic types of remanufacturer:

- OEM remanufacturers - often a process alongside their manufacturing operations;

- Third-party remanufacturers - remanufacturing under licence for the OEM and often, but not always with their technical support; and

- Independent remanufacturers - remanufacturing other people's goods without licence or support for direct sales into the aftermarket.

\section{Springer}

(C) 2015 Ridley and ljomah. Open Access This article is distributed under the terms of the Creative Commons Attribution 4.0 International License (http://creativecommons.org/licenses/by/4.0/), which permits unrestricted use, distribution, and reproduction in any medium, provided you give appropriate credit to the original author(s) and the source, provide a link to the Creative Commons license, and indicate if changes were made. 
The key difference, in the context of this research, between independent remanufacturers and OEM and contract remanufacturers is in terms of cores. Cores are the used products at the end of their working life. In almost all cases for the contract and OEM remanufacturer the customers are responsible for return of cores with the remanufacturer having little control over the quantity, mix or quality of returns. Generally the OEM remanufacturer is separate from general production, so the OEM can be considered a customer to the remanufacturer. This can have a significant impact on ability to supply customers as the cores received cannot be guaranteed to match the mix of remanufactured units required by the customer. In addition, contract remanufacturers operate with fixed cost contracts that allow for little or no additional charge to be made for badly damaged or incorrect cores. The actual remanufacturing process varies by product and methods such as material deposition that may be appropriate for more expensive components, such as cylinder blocks, would not necessarily be suitable for remanufacturing lower cost products such as mobile phones. Nevertheless the overall process regardless of product can be described as in the Fig. 1 [10].

Many authors ([5, 6, 8, 9, 12, 14, 23, 25, 26] etc.) acknowledge that uncertainty about the quality (and often the quantity) of cores has a detrimental effect on the productivity and profitability of remanufacturers. Errington [5] describes the use of core inspection to eliminate products and components that would be either prohibitively expensive or extremely difficult to remanufacture. This is particularly useful to independent remanufacturers, especially where they do not have an identified customer for their product, but contract remanufacturers often have very little choice when specific customer demand exists regardless of the supplied quantity or quality of cores.

Inspection is a fundamental part of any remanufacturing process $([7,11,18,19]$ etc.). It is usual practice in remanufacturing to inspect at many stages through the process, often functionally and in all cases visually. Brent and Steinhilper [2] as well as Ijomah [11] amongst others state that $100 \%$ inspection is always required at one or more of the remanufacturing phases. The result of this is a high quality product for customers but lowered profitability for the remanufacturer. This is due to the uncertainty concerning the quality and condition of the returned products. Literature suggests that there is a strategic benefit in core sorting [17] and recommend grading cores for quality to improve the disassembly

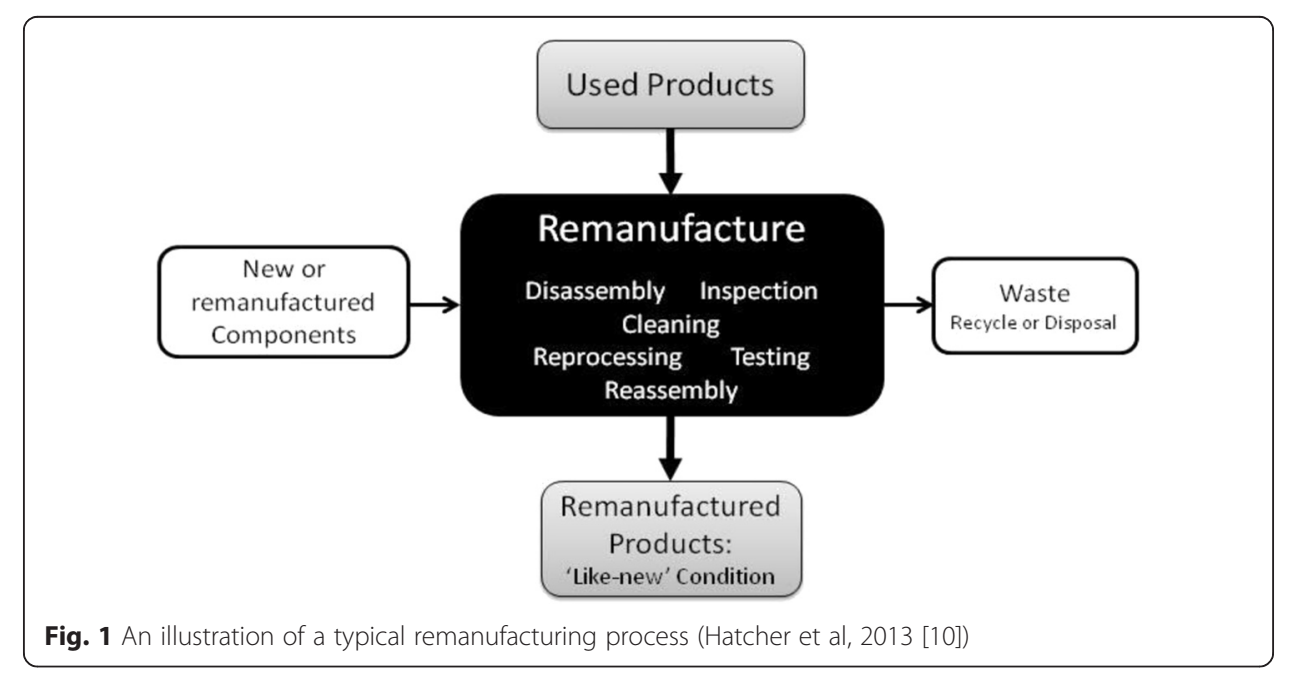


process [5]. Teunter [25] go further and propose four grades of cores as part of their acquisition policy. All these authors note that there is a benefit (unquantified) to remanufacturers when they are able to process high quality cores.

This research, to determine whether and by how much the overall remanufacturing process of engines could be made more efficient with a robust inspection of cores, was carried out at the Caterpillar Remanufacturing Services (a division of Caterpillar Inc.) facility in Rushden, U.K. This facility primarily remanufactured petrol and diesel engines both as an OEM for Caterpillar Inc. and as a contract remanufacturer for a variety of other OEMs. Remanufacturing is a mature business in the automotive sector and consequently offers an ideal environment for experimental research. The researcher's employment at the facility as a production manager also facilitated unprecedented access over an extended period to all aspects of the remanufacturing process.

\section{Methodology}

The research utilized a mixed mode approach where qualitative information was collected via semi- structured interviews and observations. The quantitative part of the research methodology was the use of experiments true experimentation [3]. A summary of the methodology follows due to space constraints however; further details can be obtained from Ridley [22].

\section{Independent variables}

The aim of the research was to understand whether the overall remanufacturing process could be made more efficient by a robust regime of pre-processing inspection. It was consequently important to understand which elements of the inspection resulted in the greatest benefits. Therefore the content of the pre-processing inspection, the independent variable in the experiment, was manipulated by the researcher. Four inspection protocols were developed, limited by the technology available in the remanufacturing facility. These were:

- Protocol 1: No inspection, decant, establish part number and reuse. This protocol was to test whether inspection of core made any material difference.

- Protocol 2: Decant, establish part number, brief visual, external inspection and determining one of three grading. Either, 1) Use as regular cores, 2) close to new - bypass the usual process or 3 ) severely damaged - use as a parts donor. This was the usual process and used as the baseline.

- Protocol 3 Protocol 2 plus manual rotation of moving parts, visual and scent inspection of rotating electrics and close inspection of open ports and oil ways. This latter inspection is commonly known by practitioners as the "scratch and sniff" test because burnt electric components can often be detected from their smell.

- Protocol 4 Protocol 3 plus inspection using a fibre optic endoscope to investigate the internal condition of cylinder bores, turbochargers, alternators etc.

Instructions detailing the exact work content for each individual protocol were produced and operators were given training in the specifics of each one. The output from each inspection protocol was a feedback sheet for every engine in the experiment. 
This sheet noted the unique core number, the specific OEM part number and the outcome of the inspection dependent upon the protocol used.

\section{Dependent variables}

The overriding factor in the choice of dependent variables was the ability to measure the direct effects of the experimental treatments. Processing time for each remanufacturing activity, from unpacking and inspection to final post-production testing, was able to be measured both at individual component/sub-assembly level and at overall engine level and consequently became the dependent variable. An engine is an assembly of individual components and smaller assemblies and, as a consequence, provided opportunities to establish whether the experimental treatments were equally effective on a variety of differing materials, complexities and scales. Measurement of the overall processing time would establish whether the benefits of the inspection protocols outweighed the scale of the intervention. Four engines were selected, representing a variety of customers and a relatively large volume of product. The selections were designed to promote the ability to generalize the findings.

- Engine A - 4 cylinder engine with a capacity of less than 2 litres. This engine was supplied to the customer at a long engine level. This comprised: cylinder block assembled with pistons, connecting-rods, crankshaft, fully assembled and timed cylinder head, oil sump, oil pump, timing gear and outer covers.

- Engine B - 6 cylinder engine of a capacity greater than 2 litres. This engine was also supplied to the customer at a long engine level comprising: cylinder block assembled with pistons, connecting-rods, crankshaft, fully assembled and timed cylinder head, oil sump, oil pump, timing gear, outer covers and vacuum pump.

- Engine C - 4 cylinder engine with a capacity greater than 2 litres. This engine was supplied to the customer at a fully dressed level. This comprised: cylinder block assembled with pistons, connecting-rods, crankshaft, fully assembled and timed cylinder head, oil sump, oil pump, timing gear, outer covers, vacuum pump, fuel lift pump, exhaust gas recirculation (EGR) valve, starter motor, alternator, flywheel, turbocharger and fuel injection equipment.

- Engine D - 6 cylinder engine with a capacity greater than 2 litres. This engine was supplied to the customer at a fully dressed level. This comprised: cylinder block assembled with pistons, connecting-rods, crankshaft, fully assembled and timed cylinder head, oil sump, oil pump, timing gear, outer covers, vacuum pump, fuel lift pump, compressor, turbocharger and fuel injection equipment.

Each activity that forms the overall remanufacturing process, disassembly, cleaning, any appropriate salvage activities, reassembly and testing was timed for each component or sub-assembly of each engine in order that any changes could be identified. In total 2196 engines were investigated.

\section{Design of experiments}

The experiments were constructed from a post-test only control group, designed using the "Solomon Four group design" method [24] as a template to ensure all variables were covered. Engines of each type were randomly assigned upon receipt, sight-unseen, to one of four groups comprising of that engine type only. Four common pre-processing 
inspection protocols were then applied, one to each group, and the processing times for each activity measured. Both the protocols and their application were randomised and so at any one time engines of all four types subjected to any one of all four protocols were passing through the facility. The research design assumes that inspection protocol 2, which is the existing level of pre-inspection prior to the experiments being conducted, is the equivalent of no treatment and that all groups subjected to this protocol form the control group. Essentially this is just a transfer of the control from the experimental groups and to the treatment. In all cases, $\mathrm{R}$ represents randomisation of the group, $\mathrm{X}$ represents a treatment, a pre-processing protocol, $\left(\mathrm{X}_{1}, \mathrm{X}_{2}\right.$ etc.) and $\mathrm{O}$ represents a group, an engine in this research $\left(\mathrm{O}_{1}, \mathrm{O}_{2}\right.$ etc.). The overall design is represented in Fig. 2.

This design satisfies all the concerns of validity: having a control group, involving the manipulation of one independent variable and measuring all of the dependent variables. It also satisfies the recommendations of Charness et al. [4] by combining betweensubject and within-subject design.

\section{Randomisation of subjects}

Randomisation of the experimental subjects was an essential part of the experiment in order that both the internal and external validity be maintained. Cores typically arrived at the Rushden remanufacturing facility from collection sites after consolidation. No information was available concerning the condition, quality or use history for any cores. Cores were often shipped under generic part numbers that encompassed a range of similar engines rather than by individual part number, a consequence of the earlier consolidation process. This meant that the cores were a random mix both of specific part number and of condition. Each core was randomly assigned a unique tracking number and all components removed were identified with that number.

The decision to assign a protocol at receipt but not to inspect until a core was required for production was driven by two factors: the need to disrupt normal working practices as little as possible, and the need to minimise the cost impact of the

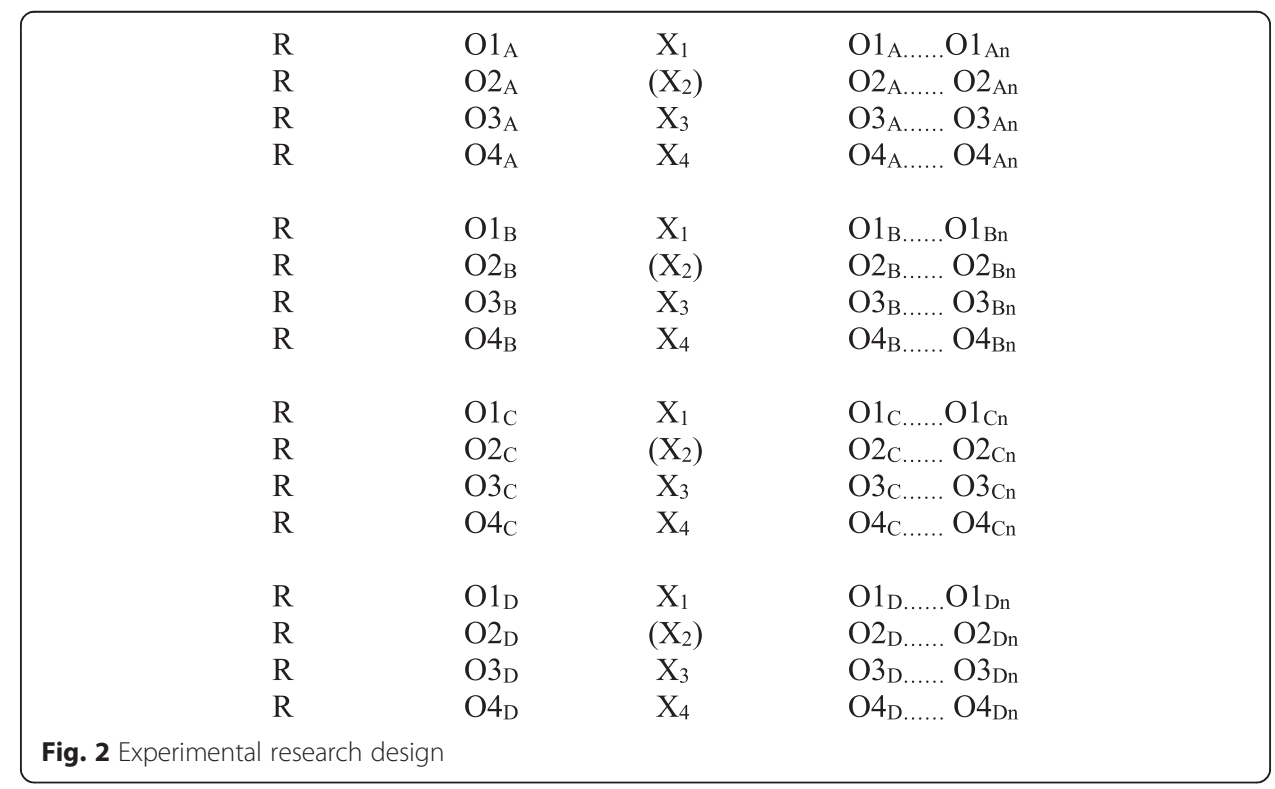


experiment. Disruption of normal working practices more than was necessary to administer the treatments was undesirable because it might introduce unforeseen variables that could contaminate the results. The allocation of a unique tracking number ensured that once the engine was passed to disassembly none of the up-stream operatives were able to determine which inspection protocol had been applied to which engines or components. This further anonymity aided internal validity as operatives could not alter their behaviour based on any assumptions about the components being processed. All activities were kept within normal production boundaries in order that individual operators could exert no influence on the outcome of the experiments.

\section{Data collection and integrity}

The nature of the experiment and the quantity of cores involved meant that a considerable amount of data would be collected. It would be impossible for one person to collect all of the results, particularly as many of the operations were undertaken simultaneously. The primary concern therefore became the ability to ensure data integrity if the collection of processing times was dispersed amongst operators. Processing times were captured in decimal minutes and collated in spreadsheet form for analysis. The data collection required for this experiment was part of the data normally collected by operators and consequently the only additional requirement was that the unique tracking number was recorded alongside the processing time. A slight change to the recording sheet made this a simple adjustment for operators. All the operators involved noted the times against the unique tracking numbers. Operators were instructed to record the time displayed on the stopwatch at the end of the process exactly as displayed and not to round up or down. Processing times included all operations that a component was subjected to during that activity where the operator was involved. Therefore cycle times in machines such as wash machines where there was no operator involvement were not recorded as part of the processing time but if the operator was required to be present the entire time, for instance during the post-production test, this period was included in the processing time.

\section{The experimental audit process}

An audit process to check data recorded by operators was already in place at the Rushden facility and a more frequent version of this system was used to verify the data collection. Using this system ensured that operatives experienced working conditions that were as near as possible to usual. This was important to ensure that operators did not alter their behaviour because of the experiments and in some way influence the data collected. Sample size was calculated on the basis of the predicted data population of around 30,000 entries. The large amount of data being collected (the entire population rather than a sample) meant that there was high confidence that any statistical significance would be directly attributable to treatments and consequently setting the $\alpha$ value at 0.05 and thus the confidence at $95 \%$ could be justified [15]. The calculation of sample size based on those parameters required a $7.14 \%$ sample size or 2427.6 parts. This equated to one component in every fifteen. The existing audit scheme was modified to satisfy the requirements of the research design whilst remaining intrinsically the same in order to reassure the operators. All audits during the experimental phase were carried out by the researcher. 


\section{Results, analysis and discussion}

Results were collected and analysed for all four of the subject engines but only those for engine $\mathrm{C}$ are presented here owing to the quantity of data and journal paper length constraints. Full data and analysis can be found in Ridley [22]. The results from the across-engine analysis of all four engines showed consistent patterns across engines and engine components; consequently engine $\mathrm{C}$ was selected as it has the greatest number of constituent components and sub-assemblies can be said to be the most representative of the research as a whole.

\section{Engine $\mathrm{C}$ results}

A total of 420 type $C$ engines were examined during the experimental phase. These were randomly allocated on arrival to the four inspection protocols in the following quantities:

- Protocol 1 - 104 engines;

- Protocol 2 - 105 engines;

- Protocol 3 - 105 engines; and

- Protocol $4-106$ engines

Engine $C$ was a 4 cylinder engine with a capacity of more than 2 litres.

Table 1 shows the percentage change in mean time from the control (protocol 2) for each remanufacturing activity and each protocol.

It can be seen that whilst engines inspected to protocols 1 and 2 have a much lower time for the decant and inspect activity (the application of the protocol), the overall remanufacturing process time is higher than for those engines inspected to protocols 3 and 4, despite their longer decant and inspect activity times. In these latter two cases, the benefits greatly outweigh the additional work. The table also shows that not all activities within the remanufacturing process benefit in the same way from the increasing levels of inspection.

\section{Analysis of engine $C$ results}

The primary analysis across all the results was within-engine as this clearly demonstrated whether the treatment applied had any effect as each component set was similar. A secondary cross-engine analysis was conducted to establish similarities between engine sub-assemblies and components to better identify any commonalities that would enable a generic inspection methodology to be established. Analysis of the overall data set for each engine used IBMs Statistical Processing for Social Scientists (SPSS) package and specifically using one-way ANOVA [13]. One-way ANOVA was selected because there are four randomly selected groups (the four engine types) who together constitute the entire population. The within-engine analysis for engine $\mathrm{C}$ is presented here. The tabular and graphical outputs from SPSS are shown in full only for the overall remanufacturing process.

\section{Statistical correlation}

Statistical analysis was carried out for each activity time in the remanufacturing process for every engine studied. This was to understand whether there was a statistical 
Table 1 Percentage change in mean activity times from the control - engine C

\begin{tabular}{|c|c|c|c|c|}
\hline \multirow[t]{2}{*}{ Activity } & \multicolumn{4}{|c|}{$\%$ change in mean time from control } \\
\hline & Protocol 1 & Protocol 2 & Protocol 3 & Protocol 4 \\
\hline Decant and Inspect & -21.61 & Control & 23.66 & 85.85 \\
\hline Disassembly & 10.35 & Control & -20.06 & -20.06 \\
\hline Block Remanufacture & 3.12 & Control & 0.63 & -0.83 \\
\hline Head Remanufacture & -0.39 & Control & -3.88 & -3.10 \\
\hline Crankshaft Remanufacture & 0.03 & Control & -1.23 & -1.20 \\
\hline Camshaft Remanufacture & -0.17 & Control & 0.04 & -0.06 \\
\hline Valve Remanufacture & 0.38 & Control & 0.13 & 0.17 \\
\hline Connecting Rods & -0.01 & Control & -0.02 & 0.20 \\
\hline Rocker Shaft Remanufacture & -0.08 & Control & -0.05 & -0.10 \\
\hline Oil Pump Remanufacture & -0.01 & Control & 0.06 & -0.04 \\
\hline Fuel Lift Pump Remanufacture & 3.96 & Control & -1.33 & -0.53 \\
\hline EGR Valve Remanufacture & 1.14 & Control & -3.78 & -3.83 \\
\hline Vacuum Pump Remanufacture & 0.20 & Control & -0.08 & -0.88 \\
\hline Starter Motor Remanufacture & 7.26 & Control & -17.58 & -19.54 \\
\hline Alternator Remanufacture & 7.83 & Control & -6.68 & -9.42 \\
\hline Flywheel Remanufacture & 1.06 & Control & -1.46 & -3.10 \\
\hline Turbocharger Remanufacture & 4.15 & Control & -16.70 & -18.61 \\
\hline Small Parts Remanufacture & 5.85 & Control & -13.52 & -13.31 \\
\hline Engine Kitting & 9.31 & Control & -4.07 & -3.64 \\
\hline Engine Assembly & -0.21 & Control & -0.30 & -0.32 \\
\hline Post-Production Test & 0.19 & Control & 0.04 & 0.02 \\
\hline Paint, Pack and Despatch & -0.02 & Control & -0.04 & -0.03 \\
\hline Overall Remanufacture & 2.74 & Control & -5.36 & -5.27 \\
\hline
\end{tabular}

correlation between the increased inspection and the subsequent remanufacturing activity time. The results of this analysis for the overall remanufacturing activity time for engine $\mathrm{C}$ only are given here.

The collected data for the overall remanufacturing process for engine $\mathrm{C}$ comprised a total of 420 individual times across all four inspection protocols. These were subject to one-way ANOVA analysis giving the results shown in Table 2. The significance of the results is the confidence with which it can be said that the change in processing time was due to the effects of the differing pre-processing inspection protocol. The confidence level for the population was determined to be $95 \%$ based both upon the large size of the population and the use of data from the whole population rather than a sample [15]. Therefore the ANOVA significance figure must be lower than 0.05 for the results to demonstrate a statistically material benefit with the required $95 \%$ level of

Table 2 ANOVA output for engine C, overall processing time

\begin{tabular}{llllll}
\hline \multicolumn{6}{l}{ Overall remanufacturing process } \\
\hline & Sum of squares & Df & Mean square & F & Significance \\
\hline Between Groups & 2244064.267 & 3 & 748021.422 & 11352.218 & 0.000 \\
Within Groups & 27411.110 & 416 & 65.892 & & \\
Total & 2271475.378 & 419 & & & \\
\hline
\end{tabular}


confidence. The strength of the correlation is given by the Significance in Table 2 where the maximum correlation is 0 and the minimum correlation is 1 , therefore any result lower than 0.05 shows a strong correlation. The significance figure for the ANOVA analysis on the overall remanufacturing process for engine $C$ was 0.000 as shown in Table 2. Therefore it is possible to be confident that the effect of increasing the content of the pre-processing inspection has been a material reduction in the overall processing time of the engine.

It was previously noted that the effects of increasing the pre-processing inspection did not bring a benefit in all activities and the full analysis of each activity for engine $\mathrm{C}$ demonstrates this. As an example, Table 3 shows the difference in activity time between protocols 1 and 3 and the statistical correlation (significance) for each of the individual remanufacturing activities. Once again the strength of the correlation is given by the Significance in Table 2 where the maximum correlation is 0 and the minimum correlation is 1 , therefore any result lower than 0.05 shows a strong correlation. Negative numbers denote a decrease in time between activities times at protocols 1 and 3, positive numbers an increase.

The within-engine analysis also revealed a limit to the benefits accrued from the increasing content of the inspection protocols and this is illustrated in Fig. 3 which plots the overall remanufacturing time for every engine $C$ studied. It clearly shows that the processing time drops as the pre-processing inspection content is increased until

Table 3 Statistical correlation between protocols 1 and 3 for engine C

\begin{tabular}{lcc}
\hline Remanufacturing activity & Time difference (minutes) & Significance \\
\hline Decant and Inspect & 5.90 & 0.000 \\
Disassembly & -40.31 & 0.000 \\
Block Remanufacture & -2.92 & 0.000 \\
Head Remanufacture & -3.28 & 0.000 \\
Crankshaft Remanufacture & -0.58 & 0.000 \\
Camshaft Remanufacture & 0.04 & 0.972 \\
Valve Remanufacture & -0.08 & 0.472 \\
Connecting Rods & 0.00 & 0.879 \\
Rocker Shaft Remanufacture & 0.00 & 0.996 \\
Oil Pump Remanufacture & 0.01 & 0.995 \\
Fuel Lift Pump Remanufacture & -0.31 & 0.000 \\
EGR Valve Remanufacture & -0.56 & 0.000 \\
Vacuum Pump Remanufacture & -0.03 & 0.509 \\
Starter Motor Remanufacture & -18.78 & 0.000 \\
Alternator Remanufacture & -6.87 & 0.000 \\
Flywheel Remanufacture & -0.39 & 0.000 \\
Turbocharger Remanufacture & -33.35 & 0.000 \\
Small Parts Remanufacture & -24.09 & 0.000 \\
Engine Kitting & -14.66 & 0.000 \\
Engine Assembly & -0.34 & 0.061 \\
Post-Production Test & -0.26 & 0.114 \\
Paint, Pack and Despatch & -0.06 & 0.217 \\
Overall Remanufacture & -140.90 & 0.000 \\
\hline & & \\
& &
\end{tabular}




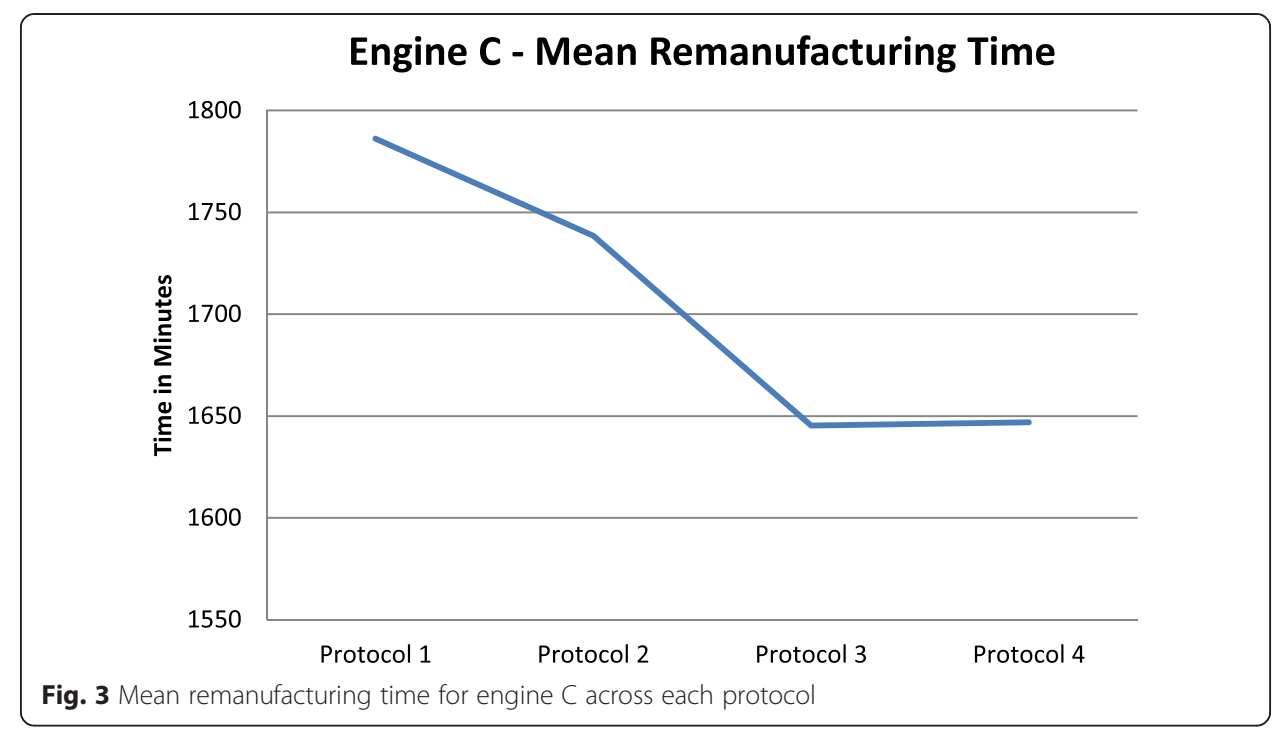

protocol 4 when the benefit is curtailed. The benefits still outweigh the additional time required for further inspection but no further benefit from inspecting additional elements than at protocol 3 is seen.

\section{Discussion}

It can be seen from the results shown that increasing the content of the pre-processing inspection activity provided a significant benefit for some components and not others. It is possible in most cases to detect underlying themes that group these components together and explain the differences.

The benefits do necessarily continue to accrue as the pre-processing inspection content increases as shown in Fig. 3 but are limited. This is because there is a finite amount of information concerning the condition of components that can be ascertained prior to disassembly and consequently once that point is reached, further inspection adds to the processing time without providing a commensurate benefit.

Significantly altered remanufacturing activities or components include: disassembly, cylinder block, cylinder head, crankshaft, alternator, fuel lift pump, EGR valve, starter motor, turbocharger, flywheel, small parts salvage and engine kitting.

These latter have at least one of the following characteristics:

- Complex geometry including internal ports;

- Large number of sub-components; or

- Constructed from or comprising of multiple materials.

These characteristics make pre-processing inspection worthwhile because they all introduce additional variables to the remanufacturing activity. Components with complex geometry are more likely to be affected by a build-up of contaminants or to experience wear or corrosion on changing surface forms. This is particularly noticeable on turbochargers where the complex blade profile experiences more corrosion than the smoother, simpler sides of the chamber despite being exposed to the same operating 
conditions. Likewise components that have either a large number of sub-components or are constructed from multiple metals can be subject to corrosion aggravated by contact between differing materials or the inconsistent wear and fatigue created by the repetitive hot and cold cycling of an engine. Water and coolant pumps often exhibit these types of wear patterns particularly around the turbine and shaft joints where the differing metals increase the corrosion at the joint.

The benefits accrue from the knowledge obtained at the point of inspection. This information was used to inform the scheduling and procurement operations enabling less material to be purchased because of assumed requirements but rather purchased against a known demand. Longer term this allowed inventory levels to reduce. This latter cannot be quantified as it was ongoing at the point at which the research ended. The knowledge gained also partly mitigated the effects of uncertainty (noted by remanufacturers as a very significant issue) because early knowledge of part number, condition and type of received cores enabled additional cores of a suitable type to be sourced in time to meet demand. The results noted for engine $\mathrm{C}$ were consistent with those seen in the other three engines and consequently it can be inferred that components with these characteristics or activities involving parts with the same demonstrate a reduction in their overall processing time but that this benefit is curtailed once the limit of information gained by inspection is reached.

The researcher's position within the remanufacturer made it possible to adopt a true experimental design $([3,21]$ etc.). This was because an external party would not have been allowed access to the extent of company information and operator time required. A control group was used to ensure internal validity. Other threats to validity were negated by the randomisation of subjects into treatment groups [1].

\section{Conclusion, research limitation and future work}

This research has identified the factors that affect decisions concerning pre-processing inspection. It concludes that for components having either complex geometry (such as internal ports), a large number of sub-components or that are constructed from, or comprising of, multiple materials, the remanufacturing process is shortened by increased inspection prior to processing. However, these benefits are currently limited by the amount of information that can be gained from the inspection methods used. The experimentation was limited by the available tools and techniques for inspecting cores and could be extended with the use of other non-destructive technology such as ultrasound testing. It was also based exclusively in the automotive sector and concerned engines and components thus new research to discover whether the factors identified were applicable to other remanufactured products would be beneficial. The main immediate thrust of further research will be to make the findings of the work accessible to those in industry by translating them into a tool to aid decision-making about appropriate pre-processing inspection.

Abbreviations

ANOVA: Analysis of variance; DEFRA: Department for Environment, Food and Rural Affairs; OEM: Original equipment manufacturer; SPSS: Statistical processing for social scientists. 


\section{Authors' contributions}

SR was the main researcher. As the PhD student she managed the research on a day to day running basis, undertaking the experiments, case study work and literature review. WLI was the research supervisor. She provided guidance on the general research process and supported the analysis of information and data. Both authors were involved in the writing of this article. Both authors read and approved the final manuscript.

\section{Acknowledgements}

The authors acknowledge with thanks that this research was part-funded by The Royal Commission for the Exhibition of 1851 and conducted through the goodwill of Caterpillar Remanufacturing Limited, Rushden.

Received: 14 August 2015 Accepted: 2 September 2015

Published online: 31 October 2015

\section{References}

1. Antony, J: Design of Experiments for Engineers and Scientists. Butterworth-Heinemann, Oxford (2003)

2. Brent, AC, Steinhilper, R: Opportunities for remanufactured electronic products from developing countries: Hypotheses to characterise the perspectives of a global remanufacturing industry. Proceedings of $7^{\text {th }}$ AFRICON Conference in Africa Vol. 2, pp. 891-896. (2004)

3. Campbell, DJ, Stanley, JC: Experimental and quasi-experimental designs for research. Rand-McNally, Chicago (1963)

4. Charness, G, Gneezy, U, Kuhn, MA: Experimental methods: between-subject and within-subject design. J. Econ. Behav. Organ. 81(2012), 1-8 (2011)

5. Errington, M: Business Processes and Strategic Framework for Inspection in Remanufacturing. PhD Dissertation, The University of Exeter, UK. (2009)

6. Fleischmann, M, Bloemhof-Ruwaard, JM, Dekker, R, van der Laan, E, van Nunen, J, Van Wassenhove, LN: Quantitative models for reverse logistics: a review. Eur. J. Oper. Res. 103, 1-17 (1997)

7. Georgiadis, P, Vlachos, D: The effect of environmental parameters on product recovery. Eur. J. Oper. Res. 157, 449-464 (2004)

8. Guide, VDR: Production planning and control for remanufacturing: industry practice and research needs. J. Oper. Manag. 18, 467-483 (2000)

9. Guide Jr, VDR, Jayaraman, V: Product acquisition management: current industry practice and a proposed framework. Int. J. Prod. Res. 38, 3779-3800 (2000)

10. Hatcher, GD, ljomah, WL, Windmill, JFC: Integrating design for remanufacture into the design process: the operational factors. J. Clean. Prod. 39(2013), 200-208 (2013)

11. Ijomah, WL: A model-based definition of the generic remanufacturing business process. PhD Dissertation: The University of Plymouth, UK (2002)

12. Inderfurth, K: Impact of uncertainties on recovery behavior in a remanufacturing Environment. International Journal of Physical Distribution \& Logistics Management 35, 318-336 (2005)

13. Iversen, GR, Norporth, H: "Analysis of Variance" Sage University Paper Series on Quantitative Applications in the Social Sciences, No. 07-001. (1987)

14. Ketzenberg, ME, van der Laan, E, Teunter, RH: Value of information in closed loop supply chains. Production \& Operations Management 15, 393-406 (2006)

15. Lipsey, MW, Hurley, SM: Design sensitivity: Statistical power for applied experimental research. In: Bickman, L, Rog, D (eds.) The SAGE Handbook of Applied Social Research Methods. Chapter 2, 2nd edn, pp. 44-76. Sage, Los Angeles (2009)

16. Lund, RT: Remanufacturing: the experience of the USA and implications for the developing countries. World Bank Technical Paper No. 3. (1984)

17. Mähl, M, Östlin, J: Lean Remanufacturing - Material Flows at Volvo Parts Flen, Masters Dissertation. Uppsala University, Sweden (2007)

18. Mukhopadhyay, $\mathrm{S}, \mathrm{Ma}, \mathrm{H}$ : Joint procurement and production decisions in remanufacturing under quality and demand uncertainty. Int. J. Prod. Econ. 120(2009), 5-17 (2008)

19. Östlin, J, Sundin, E, Björkman, M: Importance of closed-loop supply chain relationships for product remanufacturing. Int. J. Prod. Econ. 115, 336-348 (2008)

20. Parkinson, $\mathrm{HJ}$ and Thompson, G: Analysis and taxonomy of remanufacturing industry practice Proceedings of the Institution of Mechanical Engineers Vol. 217 Part E: J. Process Mechanical Engineering. (2003)

21. Polit, DF, Hungler, BP: Nursing Research: Principles and Methods, 6th edn. J. B. Lippincott, Philadelphia (1999)

22. Ridley, SJ: Increasing the Efficiency of Engine Remanufacture by Optimising Pre-Processing Inspection - A comprehensive study of 2196 engines at Caterpillar Remanufacturing in the UK. PhD Dissertation: The University of Strathclyde, UK. (2013)

23. Savaskan, RC, Bhattacharya, S, Van Wassenhove, LN: Closed-loop supply chain models with product remanufacturing. Manag. Sci. 50, 239-252 (2004)

24. Solomon, RL: An extension of control group design. Psychol Bull 46, 137-150 (1949)

25. Teunter, RH, Flapper, SDP: Optimal core acquisition and remanufacturing policies under uncertain core quality fractions. European Journal of Operational Research. (2010). doi:10.1016/j.ejor. 2010.06.015

26. Toktay, LB, Wein, LM, Zenios, SA: Inventory management of remanufacturable products. Manag. Sci. 46, 1412-1426 (2000) 